\title{
Pyrolysis of Pinus halepensis needles treated with fire retardants
}

\author{
Stylianos LiOdaKis*, Dimitris GaKis, Karita Ahlqvist, Miltos Statheropoulos \\ Department of Chemical Engineering, Sector 1, National Technical University of Athens (NTUA), 9 Iroon Polytechniou Str., 157 73, Athens, Greece
}

(Received 11 March 2003; accepted 26 February 2004)

\begin{abstract}
The effect of various chemical fire retardants: $\left(\mathrm{NH}_{4}\right)_{2} \mathrm{SO}_{4},\left(\mathrm{NH}_{4}\right)_{2} \mathrm{HPO}_{4}$, a commercial retardant contained $10 \%$ w/w phosphate salt, on the pyrolysis mass residue of Pinus halepensis needles was studied on preparative-scale. Samples of $2.00 \mathrm{~g}$ were treated under isothermal $\left(400{ }^{\circ} \mathrm{C}\right.$ and $500{ }^{\circ} \mathrm{C}$ ) and non-isothermal conditions $\left(50-500{ }^{\circ} \mathrm{C}\right)$, with pyrolysis time between $0.00-3.00 \mathrm{~h}$. The results of this study were found similar with those obtained with much lower sample sizes (i.e., $6 \mathrm{mg}$ ) used in analytical methods such as Thermogravimetry (TG). The phosphate based retardants had the most significant action, under the experimental conditions used. However, the retarding effect was reduced, when the phosphate retardants were diluted in sea water. This might be attributed to the formation of insoluble salts (i.e., $\mathrm{MgNH}_{4} \mathrm{PO}_{4}$ ). Such reactions might bind the active phosphates, thus reducing the fire retarding effect.
\end{abstract}

Pinus halepensis / needles / pyrolysis / fire retardants / sea water

Résumé - Pyrolyse du feuillage du pin d'Alep en présence de retardants du feu. On a étudié l'effet de retardants chimiques comme : $\left(\mathrm{NH}_{4}\right)_{2} \mathrm{SO}_{4},\left(\mathrm{NH}_{4}\right)_{2} \mathrm{HPO}_{4}$, et d'un retardant commercial contenant $10 \%$ w/w de sel phosphaté, sur la masse restante pendant la pyrolyse des aiguilles de Pinus halepensis, en quantités préparatoires. Des échantillons de $2,00 \mathrm{~g}$ ont été chauffés en conditions isothermes $\left(400{ }^{\circ} \mathrm{C}\right.$ et $500{ }^{\circ} \mathrm{C}$ ) et en conditions non isothermes $\left(50\right.$ et $\left.500^{\circ} \mathrm{C}\right)$ avec un temps de pyrolyse compris entre 0,00 et $3,00 \mathrm{~h}$. Les résultats sont similaires à ceux obtenus avec une masse plus petite $(6 \mathrm{mg}$ ) comme les échantillons des méthodes analytiques (p.e., TG). Les retardants phosphatés ont une action plus importante dans notre expérimentation, mais leur action diminue quand on utilise l'eau de mer comme solvant. Ceci peut être attribué à la formation de sels insolubles comme $\mathrm{MgNH}_{4} \mathrm{PO}_{4}$. Une telle réaction pourrait lier le phosphore actif et diminuer l'effet retardant.

pyrolyse / Pinus halepensis / aiguilles / retardants / eau de mer

\section{INTRODUCTION}

Forest fires cause devastating consequences and other effects on the environment $[14,15]$. Among the various methods for fighting wildfires is the use of fire retarding chemicals applied with airplanes [19]. As fire retardant is termed any substance that by chemical or physical action reduces or inhibits combustion thereby decreasing the rate of spread and the fireline intensity of a forest fire. The long-term retardants consist of flame inhibiting chemicals dissolved in water. They remain effective even after water has been removed by evaporation. The key ingredient in these long-term retardants is the active fire retardant substance, usually referred as "active salt", which is typically either an ammonium sulphate or ammonium phosphate [12].

Pyrolysis is a very important stage in forest fire mechanism and consequently, the knowledge of how the various chemicals affect the pyrolysis procedure is significant. In general the retardant inorganic salts alter the pyrolysis mechanism, pro- moting the formation of char and water, decreasing the amount of heat and slowing the fire progression [10].

The study of the effect of various fire retardant chemicals on the pyrolysis of forest fuels can support the selection of the most effective fire retardants $[3,5]$. Analytical methods such as Differential Scanning Calorimetry (DSC), Thermogravimetry (TG, DTG), Pyrolysis-Gas Chromatography / Flame Ionisation Detector (Py-GC-FID), Pyrolysis-Gas Chromatography / Mass Spectrometry (Py-GC-MS) and Direct Inlet Mass Spectrometry (DI-MS) have been extensively used to study the effect of fire retardants on the pyrolysis of forest fuels $[2,7,13,17,20$, 21]. These studies were mainly applied on Pinus halepensis needles, which are one of the most important forest species in the Mediterranean region.

A number of criteria have been developed in order to monitor the effectiveness of fire retardants on the pyrolysis of pine needles using thermal analysis techniques [13]. These criteria quantify the effectiveness of the retardants and can be used in comparative studies. Among them are: (i) the temperature at

\footnotetext{
*Corresponding author: liodakis@central.ntua.gr
} 
which the pyrolysis commences. Temperature shift to lower values is beneficial, since the forest fuel might start decomposing at temperature below the ignition values of the volatiles evolved. (ii) The alteration of pyrolysis DSC or DTG profiles. And (iii) the mass char residue increase. This char is a graphitelike carbon residue, which burns with glowing combustion, without flame and gives a lower intensity and spread rate of the forest fire [16].

However, it should be emphasised that the above analytical methods impose limitations on the quantity and the form of the samples used. For example TG analysis required samples below $50 \mathrm{mg}$, when the particle size was 200-500 $\mu \mathrm{m}$, due to the limited volume of the sample holder. Similarly, the sample sizes used in Py-GC-MS and DI-MS were less than $10 \mathrm{mg}$ and $1 \mathrm{mg}$, respectively. These small samples used as well as the rapid removal of pyrolysis or combustion products could lead to erroneous interpretations in terms of forest fuel flammability performance in field. Consequently, the question is how important are for pyrolysis studies, factors such as sample quantity, particle size (surface area to volume) and phenomena associated with them such as mass transfer, diffusion and reaction time [1]. In recent work, thermal analysis data were correlated to flammability tests performed at lab-scale [8-11].

It is in the purpose of this work to study the effect of chemical fire retardants on the pyrolysis mass residue of Pinus halepensis needles, using preparative-scale samples (i.e., $2 \mathrm{~g}$, whole needles). Also, to examine the effect of sea water, which is frequently used in suppressing forest fires, on pyrolysis, particularly when combined with long-term fire-retardants. Finally, to compare these results with those obtained in analytical-scale studies.

\section{MATERIALS AND METHODS}

\subsection{Materials}

Pinus halepensis needles were collected from the National Technical University of Athens (NTUA) campus and were live green taken from trees. The harvest period was between September and May, where the chemical composition of pine needles remains relatively constant [18]. Ammonium sulphate $\left(\mathrm{NH}_{4}\right)_{2} \mathrm{SO}_{4}$ (AS) was a p.a. grade Merck reagent, Diammonium Phosphate $\left(\mathrm{NH}_{4}\right)_{2} \mathrm{HPO}_{4}$ (DAP) was BDH laboratory reagent, Commercial Retardant (CR) was a PhosCheck product contained 86-90\% diammonium phosphate (DAP). The dilution level chosen for the above commercial product was quite below the manufacturer recommendation (usually 18-20\%), because we did not spray the retardant solution to the forest samples. Using the procedure described in Section 2.2 (immersing the forest species into a fire retardant solution and evaporating the solvent) we found that the most diluted solutions give the most consistent results, i.e. applying a specific quantity of retardant per gram of forest species. Sea Water Residue (SWR) was the residue of sea water collected from a seashore near to Athens.

\subsection{Samples}

The samples were prepared by the following procedure: The pine needles were first washed with deionised water and then dried for $24 \mathrm{~h}$ at $40{ }^{\circ} \mathrm{C}$ under vacuum $(50 \mathrm{mmHg})$. The temperature was kept below $40{ }^{\circ} \mathrm{C}$ in order to avoid any loss of the most volatile components of the forest fuel. Then, $9.00 \mathrm{~g}$ of the pre-washed pine-needles were treated with $1.00 \mathrm{~g}$ of the active chemical retardant i.e., $\left(\mathrm{NH}_{4}\right)_{2} \mathrm{SO}_{4}$
The retardant was applied to the needles according to the following procedure: A $200 \mathrm{~mL}$ of an aqueous solution contained $1.00 \mathrm{~g}$ of the retardant was prepared. The pine-needles were soaked into it for $1 \mathrm{~h}$, while the mixture was continuously stirred. Then, the solution was vaporized and the mass residue was dried in an oven at $40{ }^{\circ} \mathrm{C}$ under vacuum $(50 \mathrm{mmHg})$ for $48 \mathrm{~h}$. The above procedure, which is based on previous experimental work [13], was followed without the fire retardants for preparing the untreated samples.

To note that the chemicals used as well as the concentration levels chosen (grams of active retardant per gram of forest species) were similar to those applied in forest fires, under real conditions.

\subsection{Procedure}

$2.00 \mathrm{~g}$ of homogenous sample (pine needles prior and after treatment with the retardant) was pyrolysed in nitrogen atmosphere under isothermal and non-isothermal conditions, according to the following procedure:

(i) Isothermal pyrolysis: the pine-needle samples were pyrolysed isothermally at $400^{\circ} \mathrm{C}$ and $500^{\circ} \mathrm{C}$ for a certain time i.e., $15-180 \mathrm{~min}$, using a new sample each time. The above temperatures were selected, based on previous analytical data, which has shown that the temperature range of $400{ }^{\circ} \mathrm{C}-500{ }^{\circ} \mathrm{C}$ is the most representative for the pyrolysis study of pine needles $[7,13]$. The temperature control was better than $3 \%$ in the range from ambient to $500^{\circ} \mathrm{C}$. After pyrolysis the samples were removed from the oven and the mass residue was determined.

(ii) Non-isothermal (step) pyrolysis: the sample was put into the oven at ambient conditions and was heated to a certain temperature i.e., $200{ }^{\circ} \mathrm{C}$ for $0.5 \mathrm{~h}$. Then the sample was removed from the oven and the pyrolysis mass residue was determined. The residue was then heated to higher temperatures i.e., $300{ }^{\circ} \mathrm{C}$ for $0.5 \mathrm{~h}$. The same procedure was followed up to $500{ }^{\circ} \mathrm{C}$.

In addition, the thermal degradation of pure chemical retardants was studied, under the same experimental conditions, in order to determine the net effect of the retardants on the pyrolysis mass residue of pine needles.

Each experimental value presented in this work is the average value of three measurements and the reproducibility in all cases was better than $5 \%$.

\section{RESULTS}

Figure 1 shows the effect of pyrolysis time on the mass residue of untreated Pinus halepensis pine needles at $400{ }^{\circ} \mathrm{C}$ and $500{ }^{\circ} \mathrm{C}$, following the isothermal heating procedure. We have selected the temperatures of $400{ }^{\circ} \mathrm{C}$ and $500{ }^{\circ} \mathrm{C}$ based on previous analytical data, which have shown that the temperature range of $400{ }^{\circ} \mathrm{C}-500^{\circ} \mathrm{C}$ is the most representative for the pyrolysis study of pine needles. It appears that the pyrolysis time has a major effect on the mass residue between $0.0-0.5 \mathrm{~h}$, whilst a minor effect is recorded above $0.5 \mathrm{~h}$ at $400{ }^{\circ} \mathrm{C}$. No effect at all is observed above $0.5 \mathrm{~h}$ at $500{ }^{\circ} \mathrm{C}$. This leads to the conclusion that the pyrolysis time should be kept above $0.5 \mathrm{~h}$, in order to eliminate the effect of the parameter time in the mass residue measurements. Obviously, the evolution of the volatile products and therefore the mass residue changes last more than $1.0 \mathrm{~h}$, if the pyrolysis temperature is below $400{ }^{\circ} \mathrm{C}$ (i.e., $300{ }^{\circ} \mathrm{C}$ ). In contrast, the evolution of volatiles is completed at times below $0.5 \mathrm{~h}$, when the isothermal temperature operation is above $500{ }^{\circ} \mathrm{C}$ (i.e., $600{ }^{\circ} \mathrm{C}$ ). 


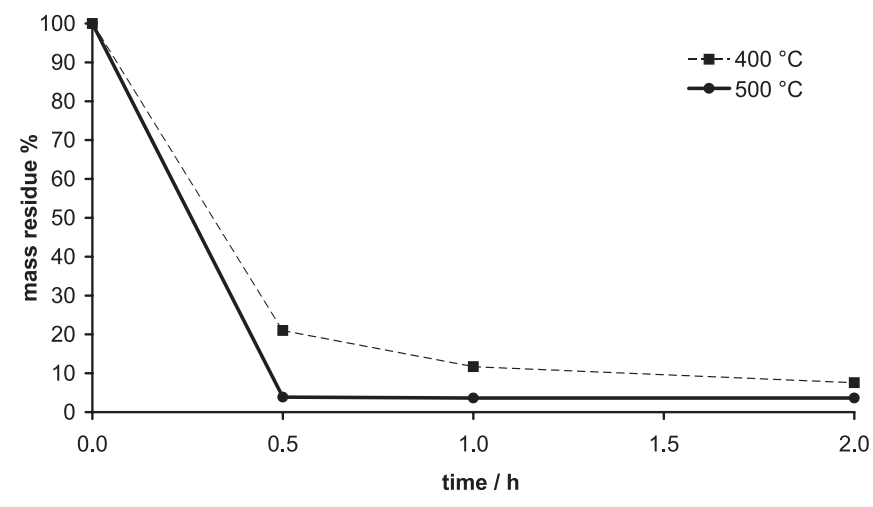

Figure 1. Isothermal pyrolysis of Pinus halepensis needles at $400{ }^{\circ} \mathrm{C}$ and $500{ }^{\circ} \mathrm{C}$. The effect of time on the mass residue.

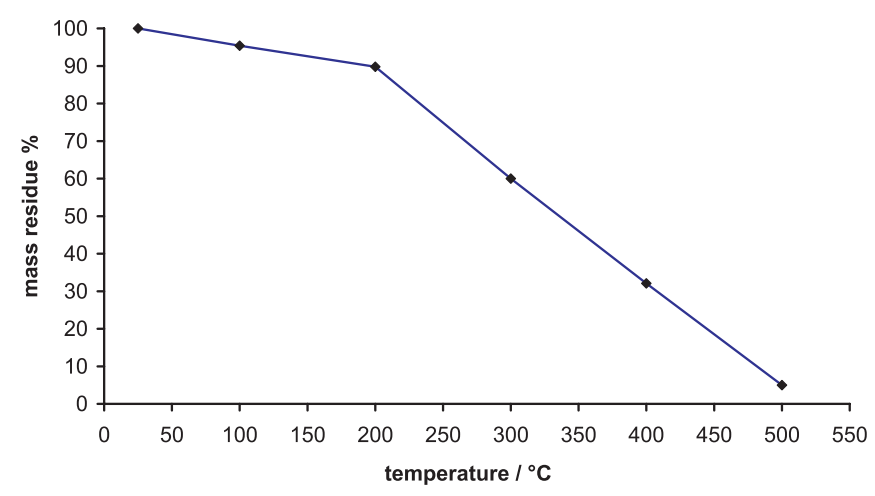

Figure 2. Non-isothermal (step) pyrolysis of Pinus halepensis needles in the range of $50-500{ }^{\circ} \mathrm{C}$ for $0.5 \mathrm{~h}$ operation in each step. The effect of temperature on the mass residue.

The effect of pyrolysis temperature on the mass residue of pine needles, within $0.5 \mathrm{~h}$ non-isothermal treatment, is shown in Figure 2. At temperatures below $200{ }^{\circ} \mathrm{C}$ minor changes were recorded. Then, the mass residue decreases significantly and reaches $5 \%$ of its initial value at $500{ }^{\circ} \mathrm{C}$. These mass residue changes are consistent with the TG analysis data [7,9]. The deviation that was sometimes observed at high temperatures (i.e., 400-500 ${ }^{\circ} \mathrm{C}$ ) can be attributed to the parameter time, which becomes very important in the region of $0.0-0.5 \mathrm{~h}$ (Fig. 1). The above comparison with the TG data provides an indication that the quantity and the form of the sample do not have a significant effect on the pyrolysis process, under the experimental conditions used.

Figure 3 shows the pyrolysis mass residue profile of the pure chemical retardants (active salts) used in this work, at different temperatures. As is shown in the graph, DAP and CR starts decomposing around $100^{\circ} \mathrm{C}$, while $\mathrm{AS}$ at temperatures around $200^{\circ} \mathrm{C}$. In contrast, SWR shows high thermal stability. Its slight mass loss observed between $100-500{ }^{\circ} \mathrm{C}$ can be attributed to the volatile salts evolved. Similar results with those presented in Figure 3 were obtained by TG analytical methods [7]. The above measurements of the pure chemical retardants were used to determine the net effect of the retardants on the pyrolysis

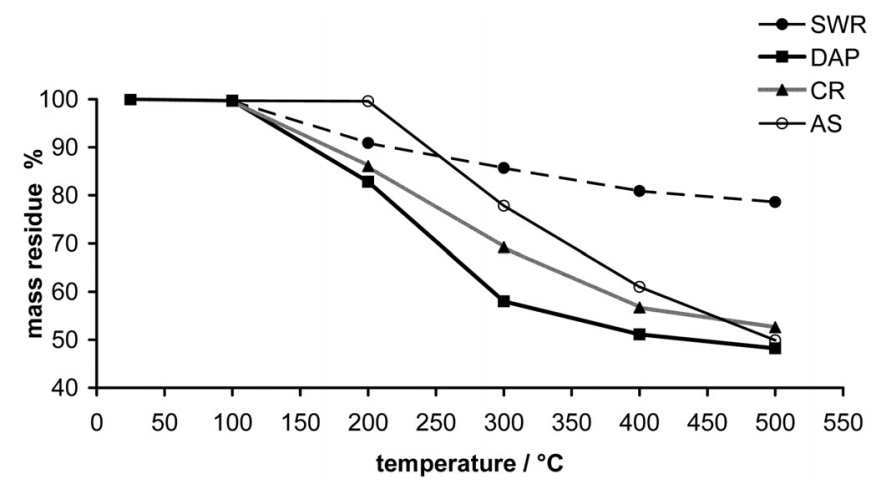

Figure 3. Non-isothermal (step) pyrolysis of the chemical retardants DAP, AS, CR, SWR, in the range of $25-500{ }^{\circ} \mathrm{C}$ for $0.5 \mathrm{~h}$ operation in each step. The effect of temperature on the mass residue.

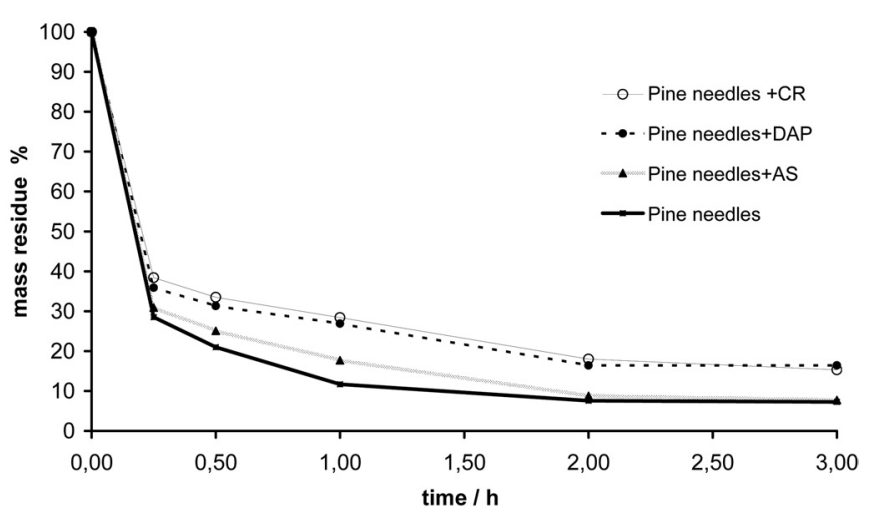

Figure 4. Isothermal pyrolysis of Pinus halepensis needles treated with DAP, AS, CR at $400{ }^{\circ} \mathrm{C}$, using various pyrolysis times $(0-3 \mathrm{~h})$. The net effect of fire retardants on the mass residue.

mass residue of pine needles. This is obtained by subtracting the mass residue of the retardant from the mass residue of the pine needles.

The effect of DAP, AS and CR on the pyrolysis mass residue of pine needless at $400{ }^{\circ} \mathrm{C}$, under various pyrolysis times is shown in Figure 4. It appears that CR has comparably the higher effect on the mass residue, DAP has very similar action, whilst AS has resulted to lower mass residues changes. Also, DAP and CR performed mainly in the range of $0.25-3.0 \mathrm{~h}$, whilst AS acts earlier between $0.25-2.0 \mathrm{~h}$. It should be noted that the measurements in any case had reproducibility better than $5 \%$.

In Figure 5 the effect of the fire retardants on the pyrolysis mass residue is presented in the temperature range of 300 $500{ }^{\circ} \mathrm{C}$, after $0.5 \mathrm{~h}$ thermal treatment. We had chosen the time interval of $0.5 \mathrm{~h}$ in order to have consistent mass residue data. $\mathrm{CR}$ showed the greatest efficiency at temperatures above $400{ }^{\circ} \mathrm{C}$. Similar results were obtained with DAP, whilst AS had the least pronounced effect. These are in a general agreement with the results obtained from TG [7].

Figures 6, 7 and 8 show the retarding effects of DAP, AS and CR respectively, when used in combination with seawater, at various temperatures. The presence of sea water appears to reduce the retarding effect of DAP and $\mathrm{CR}$, at temperatures 


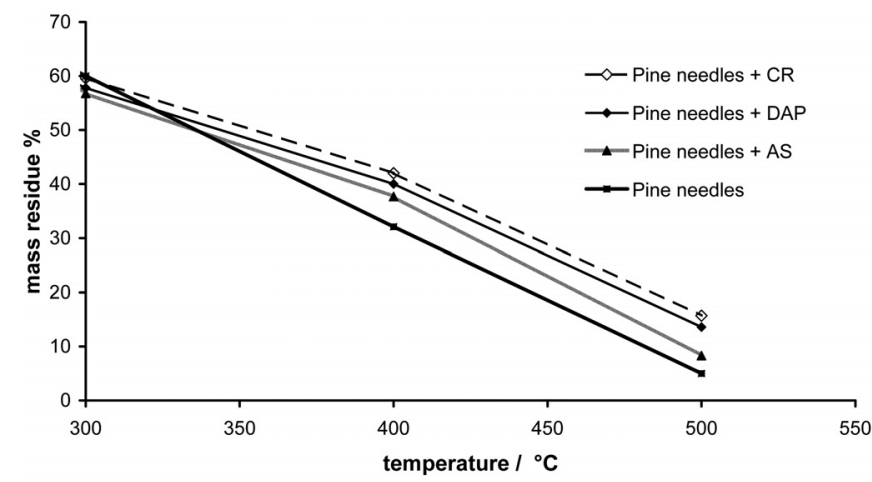

Figure 5. Non-isothermal (step) pyrolysis of Pinus halepensis needles treated with DAP, AS, CR, in the range of $300-500{ }^{\circ} \mathrm{C}$ for $0.5 \mathrm{~h}$ operation in each step. The net effect of fire retardants on the mass residue.

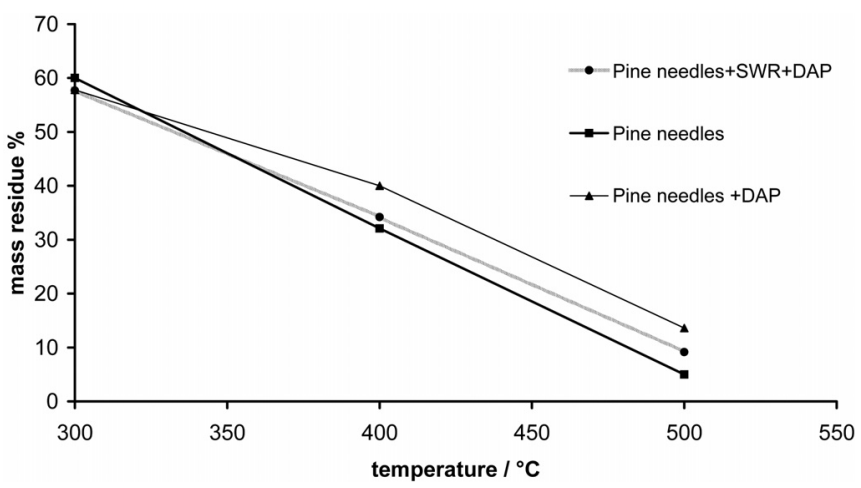

Figure 6. Non-isothermal (step) pyrolysis of Pinus halepensis needles treated with DAP. The effect of sea water on the fire retarding action of DAP.

above $350^{\circ} \mathrm{C}$. This might be attributed to the formation of insoluble salts (i.e., $\mathrm{MgNH}_{4} \mathrm{PO}_{4}$,), which hamper the retarding action. Less noticeable was the effect of seawater on the AS retarding behaviour (Fig. 8).

\section{DISCUSSION}

It is generally accepted that chemical retardants alter the pyrolysis mechanism of forest fuel, promoting the formation of char and water, and producing less volatile flammable products. Therefore, the increase of pyrolysis mass residue on the presence of fire retardants is a very important criterion for evaluating fire retardants.

In this work, the effect of temperature and time on the pyrolysis mass residue of pine needles in the presence of fire retardants was examined, using preparative-scale samples (2 g). Using mass residue as criterion for monitoring the effect of chemical retardants on the pyrolysis of pine needles a number of conclusions can be derived.

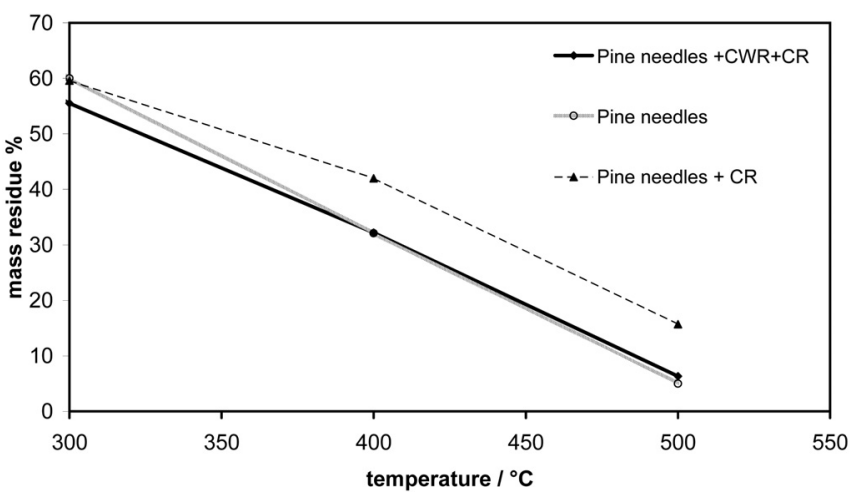

Figure 7. Non-isothermal (step) pyrolysis of Pinus halepensis needles treated with CR. The effect of sea water on the fire retarding action of CR.

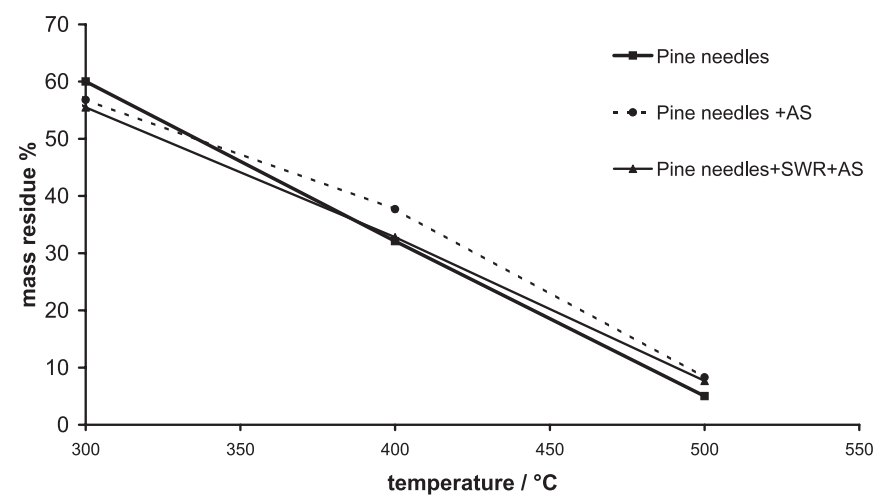

Figure 8. Non-isothermal (step) pyrolysis of Pinus halepensis needles treated with AS. The effect of sea water on the fire retarding action of AS.

First, no significant difference on the mass residues was recorded for the untreated and treated pine needles, when temperatures were lower than $300{ }^{\circ} \mathrm{C}$. The most significant mass residue differences occur when the pyrolysis temperature and pyrolysis time were set between $400-500{ }^{\circ} \mathrm{C}$ and $0.5 \mathrm{~h}$, respectively (Fig. 5).

Under these experimental conditions: temperatures between 400-500 ${ }^{\circ} \mathrm{C}$ and pyrolysis time $0.5 \mathrm{~h}$, the phosphate-based retardants appear to have the most significant effect. This is in general agreement with other works [16] and is also reconfirmed by previous studies, using various analytical methods and different sample sizes [7, 13, 17].

The effect of fire retardants based on $\left(\mathrm{NH}_{4}\right)_{2} \mathrm{HPO}_{4}$ (DAP) can be explained by its thermal decomposition, which is according to the scheme:

$$
\begin{aligned}
& \left(\mathrm{NH}_{4}\right)_{2} \mathrm{HPO}_{4} \rightarrow \mathrm{NH}_{3}+\mathrm{NH}_{4} \mathrm{H}_{2} \mathrm{PO}_{4} \\
& \mathrm{NH}_{4} \mathrm{H}_{2} \mathrm{PO}_{4} \rightarrow \mathrm{NH}_{3}+\mathrm{H}_{3} \mathrm{PO}_{4} \\
& 2 \mathrm{H}_{3} \mathrm{PO}_{4} \rightarrow \mathrm{H}_{2} \mathrm{O}+\mathrm{H}_{4} \mathrm{P}_{2} \mathrm{O}_{7} \\
& \mathrm{H}_{4} \mathrm{P}_{2} \mathrm{O}_{7} \rightarrow 2 \mathrm{H}_{2} \mathrm{O}+\mathrm{P}_{2} \mathrm{O}_{5} .
\end{aligned}
$$


The presence of phosphoric acid and phosphorous pentoxide would cause an earlier dehydration of cellulose through reaction with hydroxyl groups of glucosan units. Ammonia also could facilitate the decomposition by reacting with intermediate carbonyl compounds to form glycosylamines or Sciff bases [7].

The retardation effect of $\left(\mathrm{NH}_{4}\right)_{2} \mathrm{SO}_{4}$ (AS) was less pronounced than the phosphate based retardants, however, its action can be explained similarly to $\left(\mathrm{NH}_{4}\right)_{2} \mathrm{HPO}_{4}$, according to the following reactions:

$$
\begin{aligned}
& \left(\mathrm{NH}_{4}\right)_{2} \mathrm{SO}_{4}(s) \rightarrow \mathrm{NH}_{3}+\mathrm{NH}_{4} \mathrm{HSO}_{4}(l) \\
& \mathrm{NH}_{4} \mathrm{HSO}_{4}(l) \rightarrow \mathrm{NH}_{3}+\mathrm{SO}_{2}+1 / 2 \mathrm{O}_{2}+\mathrm{H}_{2} \mathrm{O}
\end{aligned}
$$

A comparison of the above findings with the other experiment works showed that the size and the quantity of the sample do not have a significant effect on the pyrolysis of pine needles, under the experimental conditions examined in this study [7, 13]. However, the study of fire retardants in preparative-scale seems to have the advantage over the analytical methods, of the larger samples used. This can results in measurable differences of pyrolysis mass residues, when combinations of various fire retardants are used. In addition the fractionation/selection of volatile products as well as the selection of tar and char for further analysis is feasible under these preparative- scale conditions.

It was also found in this work that the sea water residue itself has a minor effect on the pyrolysis of pine needles. This was unexpected because it has been reported that the sodium salts present in sea water catalyse the thermal decomposition of cellulose, reducing the formation of levoglucosan (1,6-anhydroglucopyranose) and increasing the occurrence of char - forming reactions $[4,6]$. However, when DAP is diluted in sea water the pyrolysis mass residue is getting less compared to that appeared when DAP is diluted in distilled water. Similar results were obtained when CR was combined with seawater. This effect might be attributed to the formation of insoluble phosphate or sulphate salts. Such reactions might bind the active phosphates, thus reducing their fire retarding effect.

\section{REFERENCES}

[1] Dimitrakopoulos A.P., Panov P.I., Pyric properties of some dominant Mediterranean vegetation species, Int. J. Wildland Fire 10 (2001) 23-27.

[2] Faroq A.A., Price D., Milnes G.J., Use of gas chromatographic analysis of volatile products to investigate the mechanisms underlying the influence of flame retardants on the pyrolysis of cellulose in air, Polym. Degrad. Stab. 33 (1991) 155-170.

[3] Green J., An Overview of the fire retardant chemicals industry, past - present - future, Fire Mater. 19 (1995) 197-204.
[4] Jakab E., Faix O., Till F., Szekely T., The effect of cations on the thermal decomposition of lignins, J. Anal. Appl. Pyrolysis 25 (1993) 185-194.

[5] Kirscbaum G., Minerals on fire- Flame-retardants look to mineral solutions, Ind. Miner. 9 ( 2001) 61-67.

[6] Kleen M., Gellerstedt G., Influence of inorganic species on the formation of polysaccharide and lignin degradation products in the analytical pyrolysis of pulps, J. Anal. Appl. Pyrolysis 35 (1993) 15-41.

[7] Liodakis S.E., Statheropoulos M.K., Tzamtzis N.E., Pappa A.A., Parissakis G.K., The effect of salt and oxide-hydroxide additives on the pyrolysis of cellulose and Pinus halepensis pine needles, Thermochim. Acta 278 (1996) 99-108.

[8] Liodakis S., Bakirtzis D., Lois E., Gakis D., The effect of $\left(\mathrm{NH}_{4}\right)_{2} \mathrm{HPO}_{4}$ and $\left(\mathrm{NH}_{4}\right)_{2} \mathrm{SO}_{4}$ on spontaneous ignition properties of Pinus halepensis pine needles, Fire Safety J. 37 (2002) 481-494.

[9] Liodakis S., Bakirtzis D., Dimitrakopoulos A., Ignition characteristics of forest species in relation to thermal analysis data, Termochim. Acta 390 (2002) 83-91.

[10] Liodakis S., Bakirtzis D., Lois E., TG and autoignition studies on forest fuels, J. Therm. Anal. Cal. 69 (2002) 519-528.

[11] Liodakis S., Bakirtzis D., Vorissis D., Autoignition and thermogravimetry of forest species treated with fire retardants, in: Viegas D.G. (Ed.), Proc. 4th Int. Conf. on Forest Fire Research, November 18-23, 2002, Luso-Coimbra, Portugal, Millpress Science Publishers, Rotterdam, The Netherlands (on CD).

[12] Lyons J.W., The Chemistry and Uses of Fire Retardants, R.E. Krieger Publishing Company, Malabar, FL, 1987.

[13] Pappa A.A., Tzamtzis N.E., Statheropoulos M.K., Liodakis S.E., Parissakis G.K., A comparative study of the effects of fire retardants on the pyrolysis of cellulose and Pinus halepensis pine needles, J. Anal. Appl. Pyrolysis 31 (1995) 85-108.

[14] Reyes O., Casal M., The influence of seed age on germinative response to the effects of fire in Pinus pinaster, Pinus radiata and Eucalyptus globules, Ann. For. Sci. 58 (2001) 439-447.

[15] Reyes O., Casal M., Effect of high temperatures on cone opening and on the release and viability of Pinus pinaster and $P$. radiata seeds in NW Spain, Ann. For. Sci. 59 (2002) 327-334.

[16] Sekiguchi Y., Shafizadeh F., The effect of inorganic additives on the formation, composition, and combustion of cellulosic char, J. Appl. Polym. Sci. 29 (1982) 1267-1286.

[17] Statheropoulos M., Pappa A., Tzamtzis N., Parissakis G., Thermal analysis of Pinus halepensis pines needles and their main components in the presence of $\left(\mathrm{NH}_{4}\right)_{2} \mathrm{HPO}_{4}$ and $\left(\mathrm{NH}_{4}\right)_{2} \mathrm{SO}_{4}$, Thermochim. Acta 261 (1995) 165-173.

[18] Sussot R.A., Thermal behavior of conifer needle extractives, Forest Sci. 26 (1980) 347-360.

[19] Tome M., Borrego C., Fighting wildfires with retardants applied with airplanes, in: Viegas D.G. (Ed.), Proc. 4th Int. Conf. on Forest Fire Research, November 18-23, 2002, Luso-Coimbra, Portugal, Millpress Science Publishers, Rotterdam, The Netherlands (on CD) - abstract p. 33.

[20] Tzamtzis N., Liodakis S., Pappa A., Statheropoulos M., Parissakis G., The effect of $\left(\mathrm{NH}_{4}\right)_{2} \mathrm{HPO}_{4}$ and $\left(\mathrm{NH}_{4}\right)_{2} \mathrm{SO}_{4}$ on the composition of volatile organic pyrolysis products of cellulose: Py-GC studies, Polym. Degrad. Stab. 56 (1997) 287-290.

[21] Yunchu H., Peijang Z., Songsheng Q., TG-DTA studies on wood treated with flame-retardants, Holz Roh- Werkst. 58 (2000) 35-38. 